\title{
O Pacto pela Saúde e o Fundo Municipal de Saúde de Várzea Paulista
}

\section{Health Pact and the Municipal Health Fund of Várzea Paulista}

\author{
Luís Fernando Nogueira Tofani \\ Cirurgião-dentista, especialista em Saúde Coletiva e em Gestão \\ Pública. Supervisor do Departamento de Gestão e Planejamento. \\ Secretaria de Saúde de Várzea Paulista. \\ Endereço: Rua Célio Barbosa, 65, Vila Santa Terezinha, CEP 13220- \\ 100, Várzea Paulista, SP, Brasil. \\ E-mail: luis.tofaniळgmail.com \\ Maria do Carmo Cabral Carpintéro \\ Médica Sanitarista. Secretária Municipal de Saúde. Secretaria de \\ Saúde de Várzea Paulista. \\ Endereço: Rua Célio Barbosa, 65, Vila Santa Terezinha, CEP 13220- \\ 100, Várzea Paulista, SP, Brasil. \\ E-mail: carminhasaúdeœgmail.com

\section{Vera Regina Bruno} \\ Economista. Diretora Administrativo-Financeira. Secretaria de \\ Saúde de Várzea Paulista. \\ Endereço: Rua Célio Barbosa, 65, Vila Santa Terezinha, CEP 13220- \\ 100, Várzea Paulista, SP, Brasil. \\ E-mail: vrbrumarkळyahoo.com.br
}

\section{Resumo}

A reestruturação do Fundo Municipal de Saúde de Várzea Paulista teve como objetivos: reorganizar o orçamento municipal de acordo com o Pacto pela Saúde, integrar ações do planejamento e gestão orçamentário-financeira, atualizar a legislação municipal e implantar sistema de monitoramento. Inicialmente foi preenchido o Termo do Limite Financeiro do Município, dividindo os recursos para custeio em 2006 por cinco blocos: Gestão, Atenção Básica, Média e Alta Complexidade, Assistência Farmacêutica e Vigilância em Saúde. Esse cálculo permitiu o planejamento do orçamento para 2007, subdividindo-se cada bloco em cinco itens de despesa (pessoal, obras, serviços de terceiros, material de consumo e permanente) acrescentando-se projetos novos. Foi aprovada lei que alterou o Plano Plurianual (PPA), compatibilizando-o com a Lei Orçamentária Anual para 2007, instituindo cinco planos de trabalho com as respectivas dotações para os itens de despesa, subsidiando a elaboração da Programação Anual para 2007. Em setembro de 2007, já com o acompanhamento financeiro-orçamentário em andamento, elaborou-se a partir de um processo de Planejamento Ascendente a proposta de prioridades para 2008 que, revertidas em necessidades financeiras, transformou-se em proposta orçamentária e converteu-se na Lei Orçamentária 2008. A reorganização do Fundo Municipal de Saúde de Várzea Paulista em cinco blocos de financiamento tem propiciado uma maior interface entre o planejamento e a gestão, com previsão, programação, monitoramento e execução orçamentário-financeira condizentes com as diretrizes e metas estabelecidas no Plano Municipal de Saúde e nas Programações Anuais.

Palavras-chave: Gestão em Saúde; Gestão financeira; Planejamento em saúde; Saúde pública. 


\section{Abstract}

The restructuring of the Municipal Health Fund of Várzea Paulista aimed to reorganize the municipal budget according to the Health Pact, to integrate planning and financial management, to modernize the municipal law and to implement a monitoring system. First, the Municipal Financial Limit Document was filled in, dividing the financial resources of 2006 among five groups: Management, Primary Care, Specialized Care, Pharmaceutical Care and Health Surveillance. This calculation helped in budget planning for 2007 , and each group was subdivided into five expenditure items (personnel, construction, outsourced services, equipment and consumption materials), besides new projects. A law that altered the Pluriannual Plan according to the Annual

Budget Law for 2007 was passed, introducing five work plans and subsidizing the development of the Annual Program for 2007. In September 2007, in an Ascendant Planning process, a priority list was converted into cost needs for the Budget Law for 2008. The reorganization of the Municipal Health Fund of Várzea Paulista into five groups has made planning and management comply with the objectives of the Municipal Health Plan and Annual Programs.

Keywords: Health Management; financial management; health planning; public health

\section{Introdução}

Em 2006, com a publicação das diretrizes operacionais do Pacto pela Saúde, que instituiu a transferência dos recursos federais para as ações e os serviços de saúde em cinco blocos de financiamento (Gestão, Atenção Básica, Média e Alta Complexidade, Assistência Farmacêutica e Vigilância em Saúde), a equipe gestora da Secretaria de Saúde de Várzea Paulista sentiu a necessidade de reorganizar seu Fundo Municipal de Saúde para sua operacionalização de acordo com a nova proposta, integrando o planejamento da Secretaria de Saúde (Plano Municipal de Saúde, Relatórios de Gestão e Programações Anuais, de acordo com a normatização do Planejasus) à execução financeira e à legislação orçamentária.

\section{Objetivos}

O processo vivenciado a partir das novas diretrizes e da necessidade de integrar o planejamento à gestão na Secretaria de Saúde de Várzea Paulista, em particular o planejamento, a execução e o controle orçamentáriofinanceiro, teve como principais objetivos:

- detalhar e reorganizar o orçamento municipal de acordo com os cinco blocos de financiamento propostos pelo Pacto pela Saúde;

- integrar as ações de planejamento e a gestão orçamentário-financeira, de acordo com o Planejasus, compatibilizando o Plano Municipal de Saúde ao Plano Plurianual (PPA) e as Programações Anuais às Leis de Diretrizes Orçamentárias (LDO) e Leis Orçamentárias Anuais (LOA);

- atualizar a legislação municipal;

- implantar o monitoramento da Programação Anual e do Orçamento.

\section{Metodologia}

Inicialmente foi preenchido o Termo do Limite Financeiro Global do Município, dividindo-se os recursos federais, estaduais e municipais para custeio em 2006 pelos cinco blocos do Pacto pela Saúde: Gestão, Atenção Básica, Média e Alta Complexidade, Assistência Farmacêutica e Vigilância em Saúde. Esse cálculo permitiu o planejamento do orçamento para 2007, 
subdividindo cada bloco em cinco itens de despesa (pessoal, material de consumo, material permanente, obras e serviços de terceiros), tomando por base o custeio já estabelecido e acrescentando-se os custos de implantação e de manutenção de projetos e programas novos a serem implantados, conforme demonstrado na planilha anexa.

Após debate com a Secretaria de Finanças e apoio da Procuradoria Jurídica do município, foi encaminhado projeto de Lei à Câmara Municipal que alterou o Plano Plurianual (PPA) e a Lei de Diretrizes Orçamentária (LDO), compatibilizando-os com a Lei Orçamentária Anual para 2007, planejada de acordo com o Termo de Limite Financeiro, instituindo cinco planos de trabalho de acordo com os blocos de financiamento, com as respectivas dotações para os itens de despesa correspondentes. Essas alterações propiciaram a elaboração da Programação Anual em Saúde para 2007 e a implantação de um sistema de monitoramento orçamentário e financeiro do Fundo Municipal de Saúde.

Em setembro de 2007, já com o acompanhamento financeiro-orçamentário em andamento e em associação ao monitoramento das ações da Programação Anual, elaborou-se a partir de um processo de planejamento ascendente e participativo a proposta de prioridades para 2008 que, revertidas em necessidades financeiras, transformou-se em proposta orçamentária para 2008, que, após negociação com o executivo e aprovação pelo legislativo, transformou-se na Lei Orçamentária anual 2008.

\section{Resultados}

A partir dessa nova organização, obtivemos como produtos estruturados de acordo com as previsões orçamentárias para 2007 e 2008 em cinco blocos de financiamento:

- Termo do Limite Financeiro Global do Município do Pacto pela Saúde.

- Plano Plurianual 2006-2009 (PPA) alterado.

- Lei de Diretrizes Orçamentárias 2007 (LDO) alterada.

- Lei Orçamentária Anual para 2007 (LOA).

- Programação Anual para 2007.

- Lei de Diretrizes Orçamentárias 2008 (LDO).

- Lei Orçamentária Anual para 2008 (LOA).

• Programação Anual para 2008.
- Monitoramento orçamentário e financeiro do Fundo Municipal de Saúde.

Esse processo tem permitido o conhecimento de nossa realidade financeira a partir do detalhamento dos custos pelos itens de despesas e blocos do Pacto pela Saúde, além de possibilitar integração real entre o planejamento e a gestão orçamentária. A implantação, ainda incipiente, de um sistema de monitoramento integrando prioridades, financeiro, orçamentário e indicadores vem dinamizando a gestão em saúde e subsidiando as decisões cotidianas. A negociação com as secretarias municipais de gestão pública, finanças, jurídico, além do chefe do executivo e a câmara municipal de vereadores, tem sido uma verdadeira reforma na administração pública, em que as diretrizes do SUS têm pautado mudanças institucionais importantes para a gestão municipal em saúde.

\section{Considerações Finais}

A reestruturação do Fundo Municipal de Saúde de Várzea Paulista em cinco blocos de financiamento, de acordo com o Pacto pela Saúde, tem propiciado uma maior interface entre o planejamento e a gestão, com previsão, programação, monitoramento e execução orçamentário-financeira condizentes com as diretrizes e metas estabelecidas no Plano Municipal de Saúde e nas Programações Anuais para 2007 e 2008, instituindo-se compatibilidade e coerência entre os instrumentos do Planejasus e a Legislação Orçamentária Municipal.

\section{Referências}

BRASIL. Ministério da Saúde. Portaria n 3332, de 28 de dezembro de 2006. Aprova orientações gerais relativas aos instrumentos do sistema de planejamento do SUS. Brasília, DF; 2006.

BRASIL. Ministério da Saúde. Portaria nº 399, de 22 de janeiro de 2006. Divulga o Pacto pela Saúde 2006 - Consolidação do SUS e aprova as diretrizes operacionais do referido pacto. Brasília, DF; 2006.

BRASIL. Ministério da Saúde. Portaria nº 204, de 29 de janeiro de 2007. Regulamenta o financiamento e a transferência dos recursos federais para as ações e os serviços de saúde, na forma de blocos de financiamento, com o respectivo monitoramento $e$ controle. Brasília, DF; 2007. 
VÁRZEA PAULISTA. Lei $\mathrm{n}^{\circ} 1817$, de 20 de dezembro de 2005. Dispõe sobre o Plano Plurianual para o quadriênio 2006-2009 e dá outras providências.

Várzea Paulista; 2005.

VÁRZEA PAULISTA. Lei n 1849 , de 31 de julho de 2006. Dispõe sobre as Diretrizes Orçamentárias para o ano de 2007. Várzea Paulista; 2006.

VÁRZEA PAULISTA. Lei n ${ }^{\circ} 1868$, de o8 de dezembro de 2006. Altera a Lei $n^{\circ} 1849 / 06$ que dispõe sobre as Diretrizes Orçamentárias para o ano de 2007. Várzea Paulista; 2006.

VÁRZEA PAULISTA. Lei n ${ }^{\circ} 1876$ de 29 de dezembro de 2006. Aprova o Orçamento para o ano de 2007. Várzea Paulista; 2006.

VÁRZEA PAULISTA. Lei n ${ }^{\circ} 1890$, de 23 de julho de 2007. Dispõe sobre as Diretrizes Orçamentárias para o ano de 20o8. Várzea Paulista; 2007.
VÁRZEA PAULISTA. Lei n ${ }^{\circ} 1916$, de 28 de dezembro de 2007. Aprova o Orçamento para o ano de 2008. Várzea Paulista; 2007.

VÁRZEA PAULISTA. Secretaria de Saúde. Plano Municipal de Saúde 20o6-20o8. Várzea Paulista; 2006.

VÁRZEA PAULISTA. Secretaria de Saúde. Programação Anual para 2007. Várzea Paulista; 2007.

VÁRZEA PAULISTA. Secretaria de Saúde. Programação Anual para 20o8. Várzea Paulista; 2008.

VÁRZEA PAULISTA. Secretaria de Saúde. Relatório de Gestão 2006. Várzea Paulista; 2007.

VÁRZEA PAULISTA. Secretaria de Saúde. Relatório de Gestão 2007. Várzea Paulista; 2008. 